Please quote as: Wegener, R. \& Leimeister, J. M. (2012): Virtual Learning Communities: Success Factors and Challenges. In: International Journal of Technology Enhanced Learning (IJTEL), Ausgabe/Number: 5/6, Vol. 4, Erscheinungsjahr/Year: 2012. Seiten/Pages: 383 - 397. 


\title{
Virtual learning communities: success factors and challenges
}

\author{
Information Systems, \\ Kassel University, \\ Pfannkuchstraße 1, 34121 Kassel, Germany \\ Email:wegener@uni-kassel.de \\ Email: leimeister@uni-kassel.de \\ *Corresponding author
}

René Wegener* and Jan Marco Leimeister

\begin{abstract}
Despite their didactical potential many Virtual Learning Communities (VLCs) fail in enhancing learning outcomes. Therefore, we synthesise factors most critical for establishing a successful VLC. Applying a structured literature review, we searched for studies dealing with VLCs in the well known databases Business Source Premier, Science Direct and ERIC. We identified, classified and synthesised 64 relevant papers. Results indicate that critical success factors include a strong instructor that acts in different facilitation roles, face-to-face meetings that help establishing social ties and well structured small-group assignments that scaffold the learning process. Main challenges are a lack of common goals, feelings of inhibition and technical problems. Based on the review, we offer concrete advice for instructors building up VLCs. We suggest that future research should focus on the design of methods and tools for instructors to facilitate the learning process in a less resource demanding way.
\end{abstract}

Keywords: learning; virtual community; success factors; literature review.

Reference to this paper should be made as follows: Wegener, R. and Leimeister, J.M. (2012) 'Virtual learning communities: success factors and challenges', Int. J. Technology Enhanced Learning, Vol. 4, Nos. 5/6, pp.383-397.

Biographical notes: René Wegener is a $\mathrm{PhD}$ candidate and fulltime researcher at the Chair for Information Systems at Kassel University. He received his MSc in Education in Business and Information Systems from the University of Bamberg in 2008. His research interests include virtual communities, blended learning, mobile learning and service engineering. In the course of his research, he focuses on customer integration into the learning service process.

Jan Marco Leimeister is a Full Professor of Information Systems and has been holding the Chair for Information Systems at Kassel University, Germany, since 2008. He received his postdoctoral lecture qualification (Habilitation) from TUM - Technische Universität München, Germany, for his work on hybrid value creation in the health economy in 2008. He received a $\mathrm{PhD}$ for his work on the systematic development of virtual communities for patients from Hohenheim University, Stuttgart, Germany. 


\section{Introduction to virtual learning communities}

Virtual communities have been called the 'killer application' of the Web as early as 1998 (Napoli, 1998) and have raised expectations regarding their usage in educational contexts (Wachter et al., 2000). But not all Virtual Learning Communities (VLCs) fulfil these expectations but instead suffer from low engagement. Many researchers have addressed this challenge over the past years by identifying critical success factors for establishing VLCs. We join this rank by summarising the results of these studies. Applying a structured literature review (Webster and Watson, 2002), we searched for studies dealing with VLCs in well-known databases identifying, classifying and synthesising 64 relevant papers.

Results indicate that there are several factors critical for the success of VLCs: a strong, present and helpful instructor that acts in different facilitation roles, face-to-face meetings that help to establish social ties, and small-group assignments that offer concrete goals and avoid information overload. Main challenges are a lack of common interests or goals, feelings of inhibition and technical issues.

The paper is structured as follows: we first explain the basics of VLCs. Thereafter, we introduce the research framework that served as a basis for the literature review. We then present, synthesise and discuss the results. Based on the results we identify future research challenges.

\section{Definitions and didactical basics}

\subsection{Definition of virtual learning communities}

A virtual community can be 'any virtual social space where people come together to get and give information or support, to learn, or to find company' (Preece, 2001). Social interaction is enabled by an information technology platform and members are bound together by a common purpose, goal or problem (Leimeister et al., 2004). VLCs, as the name implies, are dedicated to learning. Thus, we state that a VLC is a virtual social space enabled by an information technology platform where people with a common goal or purpose come together in order to interact with each other to gain and/or share knowledge.

However, not every kind of collaborative learning scenario can be called a community. As Dillenbourg (1999) states, collaborative learning scenarios may differ in time (from several hours to years) or in the number of learners (from small teams to courses of thousands of people). Thus, we further characterise a VLC by the fact that it lasts for a certain time period of at least several weeks and consists of more people working together than just small teams. In addition, we distinguish between two general kinds of communities which we call: 'Formal VLCs' and 'Informal VLCs'. Formal learning is what usually takes place in school classes and university courses or through certified continued education. Informal learning is more unintended, unstructured and often lacks a teacher (Eraut, 2004). In our review, we use the term informal VLC when it is not directly connected to a coherent course design. Instead, in informal VLCs, people form a community of practice (Wenger, 1998) around a special topic, distributing knowledge in a 'living' way. The members are informally bound together by their shared purpose or problem, not formally by a course instructor in a university. 
All communities incorporated in this study deal with a special topic and are dedicated to learning. Thus, larger communities, such as the well-known Wikipedia or Social Networks such as Facebook, are out of the scope of this work.

\subsection{Educational, psychological and technological aspects of virtual communities}

As VLCs form social spaces, based on an IT platform and dedicated to learning, VLC research touches many different disciplines. From an educational point of view, VLCs offer opportunities for social learning experiences. Interactions like the ones occurring between learners themselves or between learners and an instructor are crucial for the learning process (Thurmond and Wambach, 2004). Social constructivism posits that the interactions with other human beings are of special importance for learners to construct their understanding of the world (Vygotsky, 1988). In a virtual community, interaction is an inherent part and occurs in discussions between its members. They construct artefacts in dynamic group processes with the mutual engagement. Thus, VLCs seem to be ideal tools to support social learning processes.

Social interactions are enabled through the IT platform and its different tools like black boards, chats or social media. Research on virtual communities has shown that technological aspects like website stability are important for users' satisfaction and actual use of the platform (Leimeister et al., 2004). Also the selected tools should support the desired tasks. Synchronous communication tools e.g. may be better to support knowledge creation in smaller groups (Hrastinski, 2008) but might be difficult to apply in large groups.

From a psychological perspective, it is interesting to analyse the factors that drive learners to act in an intended or unintended way. One important factor that supports knowledge sharing is trust (Leimeister et al., 2005). If people do not trust each other, they are more reluctant to share knowledge which hinders an effective learning process. Technological components like user profiles may help to build trust. This example shows how the different aspects work together in VLCs. Thus, while this review focuses on the didactical purpose of VLCs, it will also take into account psychological or technological factors that might hinder interaction and learning.

\subsection{Measuring virtual learning community success}

Success of a VLC can be measured in different ways, including the degree to which participants feel they actually are members of a community, the overall learning satisfaction, plain usage of the community platform or concrete learning outcomes. Measuring learning outcomes is a complex field of research on its own. Learning success can be measured directly through tests (Kraiger et al., 1993) or indirectly through selfreports. The advantage of the latter one is that one can compare results across different courses and get insights into learners' self-evaluation. The disadvantage is that selfreported outcomes may only correlate weakly with actual learning success. Thus, they are sometimes considered being more suitable for measuring affective, i.e. motivational and attitudinal, outcomes. As there are reasonable arguments in favour for direct as well as indirect measures (Benbunan-Fich, 2010), we will include both in the review. 


\section{Research framework}

\subsection{Methodology and selection of literature}

A literature review is supposed to synthesize the most important scientific results in a special domain and to identify possible contradictions and the state of the research (Bem, 1995). In addition, by summing up previous results, white spots are to be pointed out, thereby highlighting promising areas for future research (Webster and Watson, 2002). For our research, we looked for empirical studies about VLCs in order to identify success factors and challenges in designing and establishing VLCs. We chose three well-known databases for our research: The pedagogical database ERIC (Education Resources Information Center), Business Source Premier and ScienceDirect. These databases include important journals such as the Academy of Management Learning and Education (Business Source Premier) or Computers and Education (ScienceDirect). We conducted the research in January of 2012 and our search string was ('virtual community' or 'online community') for searching through ERIC, which was supplemented with (AND 'learning') in the other databases. We restricted our search to articles from peer reviewed journals published since the year 2000. We first searched through the titles of the publications and then the abstracts to identify suitable literature. We only included empirical papers, not conceptual ones. In the end, we identified 56 articles through this research method, four in Business Source premier, 24 in ERIC and 28 in ScienceDirect. During the progress and review of this work, several external experts pointed to additional publications of interest. These recommendations led to a further eight publications which makes up a sum of 64 articles.

\subsection{Categorisation scheme}

As implied by Cooper (1998), we incorporated some background information in our categorisation scheme, i.e. the subject of the community and institutional backgrounds of the learners. Since most studies were conducted in university courses, we only distinguish between university and other backgrounds. Another important aspect we included in the scheme is its virtuality. We consider a VLC to be 'blended' if there are at least face-to-face meetings at the beginning and the end of the course and pure online if there are no face-to-face meetings. If both categories are marked with a cross, this means that the study incorporated at least two different courses.

We also categorised the studies with regard to the applied empirical research method (Cooper, 1998). These are observations, mostly through server logs, interviews, surveys and objective tests, usually university exams.

The last part of our categorisation scheme is dedicated to the success factors themselves. As implied by Webster and Watson (2002), the different concepts were not predetermined, but were successively derived from the literature itself at the time of analysing the individual papers. As success factors or challenges, we declared factors that contributed to or hindered either learning success, learners' satisfaction or perceived level of community or presence. To include a wide range of research, we were open to different measuring methods for each of these aspects. These include quantitative findings, e.g. significant differences between mean test scores of participants of a 
blended and pure online VLC, as well as qualitative findings, e.g. students stating that they benefited from the instructor's regular support. We also took into account the authors' own interpretations and conclusions in each paper.

\section{Results}

Of the 64 articles, 36 studies dealt with Formal VLCs (Table 1), 16 were classified as Informal VLCs and there were also 11 meta-studies (Table 2), with some studies examining dozens of communities each. For a better overview, we distinguish between these three kinds of studies. Most studies were conducted in university settings and topics often related to didactics and education. Similarly, the Informal VLCs we came across were often communities of practice consisting of teachers. The most common topics, in general, were educational ones (24) or topics in the area of information technologies (7). This already shows one shortcoming of current research. Since VLCs are mostly being studied by researchers from the IS or educational sector, there is not much knowledge about other topics and to what extend a VLC works better or worse in specific domains. It is noteworthy that 23 articles were published in 2010 or later which shows how much attention the topic earned over the last years.

Another interesting aspect is that only six studies actually measured objective learning outcomes. Most of them relied on server logs (observations) and surveys for success measurement. So in many studies it remains unclear whether the usage of a VLC really lead to higher learning outcomes. Especially when taking a look at Informal VLCs there are no studies actually measuring objective learning success.

We identified three main success factors and three main challenges when establishing a VLC. The presence and facilitation of the instructor, face-to-face meetings and wellstructured small-group assignments seemed to foster community feelings and learning success. Main challenges are technical issues, a lack of common goals and feelings of inhibition or lack of trust. In this way, the results represent the interdisciplinary influences on VLCs, as educational, technological and psychological aspects are intertwined at this point.

Table 1 Compilation of results (meta-studies)

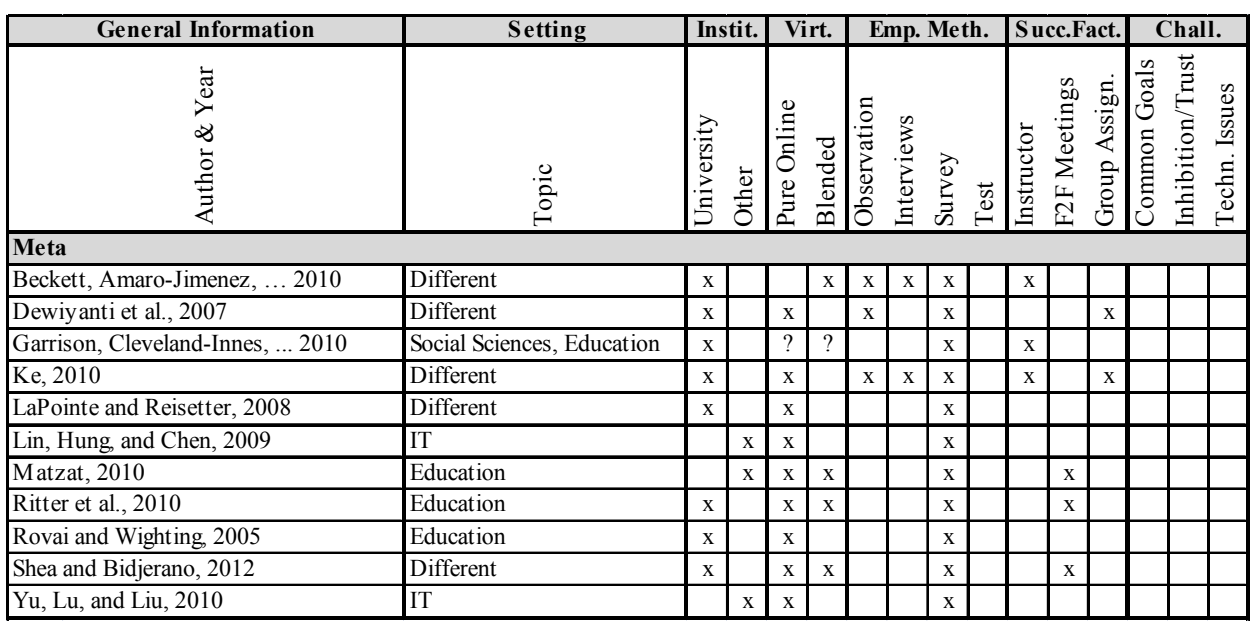


Table 2 Compilation of results (formal and informal VLCs)

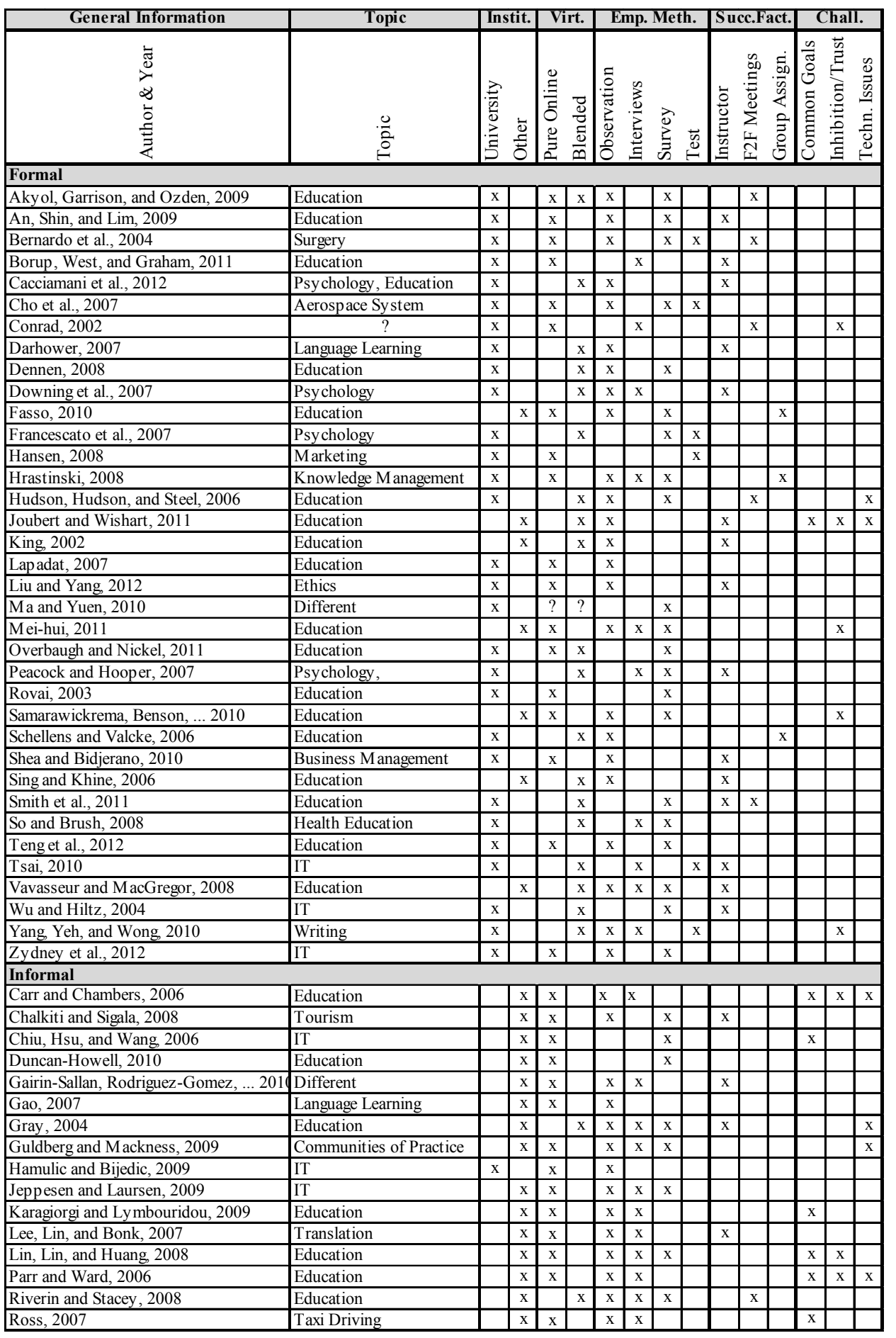




\section{Discussion of results}

Success factor 1 - facilitation and presence of the instructor: This factor refers to activities directly performed by the instructor like starting discussions, encouraging learners or offering feedback. Teaching presence strongly influences social and cognitive presence. These assumptions are supported by structural equitation modeling (Garrison et al., 2010) and content analysis of postings (Shea et al., 2010). Analysing posting behaviour, King finds that continuous interventions keep discussions flowing (King, 2002) and Liu states that hard scaffolding enhances discussion quality (Liu and Yang, 2012). Based on content analysis, Smith et al. (2011) find that some students do not understand the importance of online group work and Sing and Khine (2006) state that learners often are not used to criticise others. Both studies conclude that it is the instructor's task to explain importance and rules of online group work to participants and establish an environment where critique is accepted.

Many studies indicate that instructors' availability and high number of individual feedbacks are highly appreciated by students (Peacock and Hooper, 2007; Beckett et al., 2010; Ke, 2010; Tsai, 2010). However, these are qualitative studies based on self-reports or interviews. It is presumably natural that students prefer attainable instructors that offer lots of feedback as this makes learning more comfortable. But the results are no evidence that a certain level of attainability or feedback is necessary for effective learning as the demand for more instructor interventions may also be connected to a lack of own engagement. Comparing different kinds of instructor facilitation between three VLCs, An et al. (2009) find that mandatory peer feedback creates more interaction than too much facilitation. On the other hand, forced interactions might be less critical and deep, as learners see postings only as a duty (Dennen, 2008). As a conclusion, instructors might use socially formative assignments (like introducing oneself) in the beginning as this has shown to raise the number of posts (Downing et al., 2007). Then they should assign group tasks and grade concrete group products. That way, students are not rewarded for superficial posts and the group product will also help enhance group processes (Dewiyanti et al., 2007). Instructors should also clearly state when they will be online (Ke, 2010) and use friendly, precise (Rovai, 2003) and supportive (Cacciamani et al., 2012) communications styles. To conclude, while clear expectations, tasks and a certain level of interventions are surely important, it is unclear which level of intervention and individual feedback is the best.

Surprisingly, the central role of an instructor also applies to Informal VLCs, as the moderator is crucial here as well (Gray, 2004; Lee et al., 2007; Chalkiti and Sigala, 2008; Gairin-Sallan et al., 2010). Chalkiti and Sigala (2008) highlight the importance of moderators in order to facilitate communication. Gairin-Sallan et al. (2010) also point to the fact that the type and degree of intervention necessary will depend on the motivation and skill levels of the participants, where lower levels demand more intervention from the instructor. A strong common goal and motivation might substitute external instruction to a certain degree. In this case members themselves point to the direction to be taken.

Success factor 2 - face-to-face meetings: This factor sums up any real life meetings. Most studies analysing the importance of face-to-face meetings suggest they have several beneficial effects. Akyol, Garrison, and Ozden (2009) posit that group cohesion and perceived teaching presence are higher in a blended course. Shea and Bidjerano (2012) find higher levels of perceived presence and help seeking behavior. Matzat (2010) finds 
evidence for more willingness to participate in blended communities. Results are supported by qualitative findings stating that pace of online communications may be broken up or that face-to-face meetings help to get to know each other in the beginning (Conrad, 2002; Hudson et al., 2006). Comparing blended to online VLCs Ritter et al. (2010) find that perceived community is higher, but not perceived learning. Similarly, Overbaugh and Nickel (2011) only found weak advantages for a blended VLC in connectedness, but not satisfaction or learning. They state, however, that in the online course there was a higher attrition rate which may have biased the results. To conclude, it is not sure that blended VLCs will achieve higher learning outcomes but probably at least higher perceived presence and satisfaction. This conclusion is supported by the fact that a lack of trust occurs more often in pure online than in blended settings. This means virtual communities cannot compensate all shortcomings of the media they are based on. Usage of rich media might help, e.g. mixing asynchronous and synchronous communication tools (Teng et al., 2012) or using video clips to introduce the instructor (Borup et al., 2011). The meta-analysis also suggests that meetings may be less important in Informal VLCs, probably because in Informal VLCs members are often distributed across whole countries and meetings are just not affordable. The tables also hint at the fact that where there are no face-to-face meetings, structured assignments seem to become even more important as stated in the next section.

Success factor 3 - well structured small-group assignments: This factor comprises of two parts that are strongly connected: Assigning learners to collaborate in small groups and assigning tasks with concrete outcome expectations. Schellens and Valcke (2006) compared activities of students in online discussion groups of different sizes, coming to the conclusion that larger proportions of higher level knowledge construction are detected in smaller groups. Fasso (2010) claims that participants working in concrete partnerships on specific tasks feel more connected to the community. Hrastinski (2008) argues that synchronous communication tools support personal participation and motivation, which appears to be especially true in smaller groups. These results also seem to be supported when taking a look at studies, namely, Francescato et al. (2007) and Hansen (2008), which show that online learners performed better than their face-to-face peers: In the learning scenarios of both studies, there was not only strong facilitation, but there were also different levels of assignments containing individual, small-group, and community level work. Dewiyanti et al. (2007) suggest that demanding a concrete group product (as a result of an assignment) stimulates participants to regulate their group processes. In the study of Ke (2010), students highlighted a mixture between class and group assignments as a valued quality. The positive effect of group assignments might also be enhanced by using protocols that assign different role and tasks to different learners (Zydney et al., 2012) or by integrating reflection activities to enhance the learning process (Cacciamani et al., 2012). It is notable though that this factor is only supported by one study incorporating a blended VLC. Less structured interactions may still be suitable activities if only complementing face-to-face meetings. If interactions only occur online, however, it becomes even more important to scaffold these activities. To sum up, small-group assignments seem to be helpful for learners in several ways. First, assignments give them concrete actionable advice on what to do. Second, they reduce information overload, as learners only have to read messages from several peers instead of the whole community. Third, small group assignments that afford much communication might be more helpful in establishing social ties. 
Challenge 1 - lack of common goals or interest: This factor includes any issues caused by a lack of shared motivations. It especially holds true for informal communities where learners are not motivated by receiving a grade or certificate. However, a lack of common goals is also problematic in formal learning settings. If students are only motivated by grades, interaction might become superficial (Conrad, 2002; Dennen, 2008). Instructors should carefully consider whether their course topics and learning goals are suitable for a VLC. They should clearly express how learners should engage in the community and how this helps them to achieve the proposed learning goals (Joubert and Wishart, 2011).

Challenge 2 - inhibition/lack of trust, fear of criticism: This challenge sums up psychological issues hindering participation. They can be separated into general feelings of inhibition, e.g. feeling to be exposed to community members, and more specifically a lack of interpersonal trust. Some people feel inhibited in a VLC (Conrad, 2002). They are afraid of being criticised, hesitate to criticise others (Carr and Chambers, 2006; Lin et al., 2008) or to edit their peers' work (Yang et al., 2010). They might be afraid that contributions are not good enough, suggesting that they have to take risks when contributing, as Parr and Ward (2006) indicate. They suppose online collaboration should start in a safe environment which also supports the idea of using small group discussions where people are not exposed to all participants. This challenge mostly arises in non-university settings. One reason may be that university courses, even if conducted online, still offer a more familiar and safer environment than other settings. In addition, in university settings students are often more or less forced to participate, which means that a lack of trust may play a minor role. Feelings of inhibition also seem to be more common in pure online communities (only one of six studies mentioning this challenge was based on a blended approach), which again underlines the importance of traditional face-to-face meetings for establishing trust and classroom community. Another way may be to implement different trust-supporting components like sections containing information about the provider, or other learners (Leimeister et al., 2005).

Challenge 3-technological issues: Technological issues refer to basic problems with regard to connection stability and speed, but also to learners not being able to use different tools in the didactically intended way. Challenges are expressed by six studies. The technological barriers can be of two kinds. First, members just need a stable connection to the community platform, and should not face problems dealing with the software. These problems might have become less important over the last years when high-speed internet has spread. Second, learners need the competence to use these technologies. The tables show that technological problems did not occur in VLCs dealing with IT topics. This is probably due to the fact that these VLCs were offered to technology affine students that were used to the internet and may be social media. This highlights the importance of acquainting learners with e-learning in a step-by-step manner. The problem seems to be of less importance in formal VLCs - possibly because these are more strongly guided by an instructor, and often involve face-to-face meetings, thus making adaption to the new technology and discussing technical issues easier.

\section{Research challenges}

The main result of our research lies in indentifying the instructor as being the most crucial factor for the success of a VLC. He should carefully create and assess group 
tasks, intervene regularly, express his expectations and the importance of online group work and also offer meetings in the real world. We lack, however, knowledge about the effects of different scaffolding measures and the minimum level of individual feedback necessary. Also, most existing guidelines for instructors, such as showing presence, giving individual feedback, or assessing group products, involve a very high workload. Studies repeatedly hint at the fact that VLCs are very resource demanding for the instructor as well as for the learner (Chalkiti and Sigala, 2008; Karagiorgi and Lymbouridou, 2009) without offering much advice on how to overcome this issue. To support the instructor in his tasks, we might need a new toolset of incentivation and scaffolding measures. Peer learning activities and self-regulation tasks, supported by IT components, might help to create fulfilling learning experiences with less interventions from the instructor. As an example, students might sign a voluntary agreement that they will engage in specific ways, e.g. read comments at least once a week and contribute indepth postings at least once in two weeks. They could also have to read and rate a specific number of peer comments. A virtual avatar might remind them of these tasks. To facilitate self-reflection awareness tools could be used to visualise one's own contributions compared to others. Students neglecting to contribute may receive automated mails from the system. This way, IT tools might support self-regulation and cooperation and thus also support the instructor. In this context, one might also think of tools raising awareness of one's own current learning tasks and learning status. These tools are common in cooperative work but not in cooperative learning. If tasks, roles and responsibilities are clearly visible to everyone, this might scaffold cooperative learning.

The instructor should generally receive more relevant information about learners to get an overview of the participants' learning or collaboration processes. For example, instructors should be able to automatically identify possible lurkers or central actors in their VLC. When assigning group work, the tools might identify groups with low levels of interaction and offer automatic Email reminders for scheduled tasks. Based on metrics of Social Network Analysis like number and length of posts, views or centrality of actors, tools might reveal the most engaged participants in a VLC or the most viewed posts. These could be awarded by the instructor as a sort of incentive. While there are many visualisation tools for Social Network Analysis, they are not suited for guiding a whole course at university level and do not offer concrete advice to instructors so far.

We also lack knowledge about how different tools affect learners. There are studies dealing with the difference between synchronous and asynchronous communication. With new tools like Wikis, Blogs or shared repositories, it becomes harder to determine which tools are suited for which task. It would be interesting to analyse which specific components of each of these tools might contribute to factors like individual engagement. Fear to criticise others e.g. might be lower in a Wiki, where articles are declared as common goods, than in a personal Blog.

Apart from designing new tools for the instructor it might also make sense to work on new peer evaluation methods. Other domains where Web 2.0 has had a huge impact, such as E-Commerce, often strongly rely on peer ratings of contributions or actors. These peer ratings might contain rewards such as the status of a super-user. Currently there is not much knowledge about how these rating systems might be adapted to learning contexts. Since sanctioning lurkers or rewarding active users have shown to be important aspects in a VLC, we suppose that it is not sufficient to implement peer ratings functions of a VLC platform but that they have to be combined with further incentives. 
Although the instructor or moderator will probably always be a central actor in a VLC, new methods of incentivation and new IT components might be ways of supporting collaboration between members. We suggest that future research on VLCs should focus on the design of methods and tools that enable instructors to facilitate and guide the learning processes in a less resource demanding way.

\section{Conclusion, limitations and outlook}

This study reports the results of a structured literature review of 64 papers in order to determine critical success factors and challenges of VLCs. Results indicate that a strong instructor, face-to-face meetings and assignments for small groups are three crucial factors that lead to desirable outcomes, such as a feeling of community, satisfaction and learning success. Technological issues, a feeling of inhibition or lack of trust, and a lack of common goals or motivation, are the main challenges in VLCs. In conclusion, a community should comprise the following aspects:

- A specific goal which should be clear to every member

- Tasks and discussions that are facilitated by skilled instructors or moderators

- Opportunities for members to meet face-to-face and to work in small groups.

Our research is subject to several limitations. As our literature review is narrowed down to a number of relevant databases and terms, there is always a risk of missing articles. Accordingly, results could be further supplemented by sources that might have been left aside. So our results should only be considered as an addition to research on related fields (such as Computer Supported Collaborative Learning or E-Learning). Despite these limitations, we strongly encourage practitioners to take the above success factors and challenges into account when setting up a VLC. In further research we plan to investigate methods and tools that might support the instructor in establishing connectedness and engagement in a VLC in a more resource efficient way.

\section{Acknowledgements}

Parts of this research were funded by the German Federal Ministry of Education and Research in the project BlendedContENT (www.blendedcontent.de), FKZ 01PF08022A.

\section{References}

Akyol, Z., Garrison, D.R. and Ozden, M.Y. (2009) 'Development of a community of inquiry in online and blended learning contexts', Procedia - Social and Behavioral Sciences, Vol. 1, pp.1834-1838.

An, H., Shin, S. and Lim, K. (2009) 'The effects of different instructor facilitation approaches on students' interactions during asynchronous online discussions', Computers \& Education, Vol. 53, pp.749-760.

Beckett, G.H., Amaro-Jimenez, C. and Beckett, K.S. (2010) 'Students' use of asynchronous discussions for academic discourse socialisation', Distance Education, Vol. 31, pp.315-335. 
Bem, D.J. (1995) 'Writing a review article for Psychological Bulletin', Psychological Bulletin, Vol. 118, pp.172-177.

Benbunan-Fich, R. (2010) 'Is self-reported learning a proxy metric for learning? perspectives from the information systems literature', Academy of Managament Learning \& Education, Vol. 9, pp.321-328.

Bernardo, V., Ramos, M.P., Plapler, H., De Figueiredo, L.F.P., Nader, H.B., Anção, M.S., Von Dietrich, C.P. and Sigulem, D. (2004) 'Web-based learning in undergraduate medical education: development and assessment of an online course on experimental surgery', International Journal of Medical Informatics, Vol. 73, pp.731-742.

Borup, J., West, R.E. and Graham, C.R. (2011) 'Improving online social presence through asynchronous video', The Internet and Higher Education.

Cacciamani, S., Cesareni, D., Martini, F., Ferrini, T. and Fujita, N. (2012) 'Influence of participation, facilitator styles, and metacognitive reflection on knowledge building in online university courses', Computers \& Education, Vol. 58, pp.874-884.

Carr, N. and Chambers, D.P. (2006) 'Teacher professional learning in an online community: the experiences of the national quality schooling framework pilot project', Technology, Pedagogy and Education, Vol. 15, pp.143-157.

Chalkiti, K. and Sigala, M. (2008) 'Information sharing and idea generation in peer to peer online communities: The case of 'DIALOGOI'", Journal of Vacation Marketing, Vol. 14, pp.121-132.

Chiu, C-M., Hsu, M-H. and Wang, E.T.G. (2006) 'Understanding knowledge sharing in virtual communities: an integration of social capital and social cognitive theories', Decision Support Systems, Vol. 42, pp.1872-1888.

Cho, H., Gay, G., Davidson, B. and Ingraffea, A. (2007) 'Social networks, communication styles, and learning performance in a CSCL community', Computers \& Education, Vol. 49, pp.309-329.

Conrad, D. (2002) 'Deep in the hearts of learners: insights into the nature of online community', Journal of Distance Education, Vol. 17, pp.1-19.

Cooper, H. (1998) Synthesizing Research: A Guide for Literature Reviews, SAGE Publications, Thousand Oaks, London and New Delhi.

Darhower, M. (2007) 'A tale of two communities: group dynamics and community building in a Spanish-English telecollaboration', CALICO Journal, Vol. 24, pp.561-589.

Dennen, V.P. (2008) 'Pedagogical lurking: Student engagement in non-posting discussion behavior', Computers in Human Behavior, Vol. 24, pp.1624-1633.

Dewiyanti, S., Brand-Gruwel, S., Jochems, W. and Broers, N.J. (2007) 'Students' experiences with collaborative learning in asynchronous computer-supported collaborative learning environments', Computers in Human Behavior, Vol. 23, pp.496-514.

Dillenbourg, P. (1999) 'What do you mean by collaborative learning', Collaborative Learning: Cognitive and Computational Approaches, pp.1-16.

Downing, K.J., Lam, T-F., Kwong, T., Downing, W-K. and Chan, S-W. (2007) 'Creating interaction in online learning: a case study', ALT-J: Research in Learning Technology, Vol. 15, pp.201-215.

Duncan-Howell, J. (2010) 'Teachers making connections: online communities as a source of professional learning', British Journal of Educational Technology, Vol. 41, pp.324-340.

Eraut, M. (2004) 'Informal learning in the workplace', Studies in Continuing Education, Vol. 26, pp.247-273.

Fasso, W. (2010) 'Facilitated networking and group formation in an online community of practice', Australian Educational Computing, Vol. 25, pp.25-33.

Francescato, D., Mebane, M., Porcelli, R., Attanasio, C. and Pulino, M. (2007) 'Developing professional skills and social capital through computer supported collaborative learning in university contexts', International Journal of Human-Computer Studies, Vol. 65, pp.140-152. 
Gairin-Sallan, J., Rodriguez-Gomez, D. and Armengol-Asparo, C. (2010) 'Who exactly is the moderator? a consideration of online knowledge management network moderation in educational organisations', Computers \& Education, Vol. 55, pp.304-312.

Gao, X. (2007) 'A tale of blue rain cafe: a study on the online narrative construction about a community of English learners on the Chinese mainland', System: An International Journal of Educational Technology and Applied Linguistics, Vol. 35, pp.259-270.

Garrison, D.R., Cleveland-Innes, M. and Fung, T.S. (2010) 'Exploring causal relationships among teaching, cognitive and social presence: student perceptions of the community of inquiry framework', The Internet and Higher Education, Vol. 13, pp.31-36.

Gray, B. (2004) 'Informal learning in an online community of practice', Journal of Distance Education, Vol. 19, pp.20-35.

Guldberg, K. and Mackness, J. (2009) 'Foundations of communities of practice: enablers and barriers to participation', Journal of Computer Assisted Learning, Vol. 25, pp.528-538.

Hamulic, I. and Bijedic, N. (2009) 'Social network analysis in virtual learning community at faculty of information technologies (fit), Mostar', Procedia - Social and Behavioral Sciences, Vol. 1, pp.2269-2273.

Hansen, D.E. (2008) 'Knowledge transfer in online learning environments', Journal of Marketing Education, Vol. 30, pp.93-105.

Hrastinski, S. (2008) 'The potential of synchronous communication to enhance participation in online discussions: a case study of two e-learning courses', Information \& Management, Vol. 45, pp.499-506.

Hudson, B., Hudson, A. and Steel, J. (2006) 'Orchestrating interdependence in an international online learning community', British Journal of Educational Technology, Vol. 37, pp.733-748.

Jeppesen, L.B. and Laursen, K. (2009) 'The role of lead users in knowledge sharing', Research Policy, Vol. 38, pp.1582-1589.

Joubert, M. and Wishart, J. (2011) 'Participatory practices: lessons learnt from two initiatives using online digital technologies to build knowledge', Computers \& Education.

Karagiorgi, Y. and Lymbouridou, C. (2009) 'The story of an online teacher community in cyprus', Professional Development in Education, Vol. 35, pp.119-138.

Ke, F. (2010) 'Examining online teaching, cognitive, and social presence for adult students', Computers \& Education, Vol. 55, pp.808-820.

King, K.P. (2002) 'Identifying success in online teacher education and professional development', The Internet and Higher Education, Vol. 5, pp.231-246.

Kraiger, K., Ford, J.K. and Salas, E. (1993) 'Application of cognitive, skill-based, and affective theories of learning outcomes to new methods of training evaluation', Journal of Applied Psychology, pp.311-328.

Lapadat, J. (2007) 'Discourse devices used to establish community, increase coherence, and negotiate agreement in an online university course', Journal of Distance Education, Vol. 21, pp.59-92.

Lapointe, L. and Reisetter, M. (2008) 'Belonging online: students' perceptions of the value and efficacy of an online learning community', International Journal on E-Learning, Vol. 7, pp.641-665.

Lee, M.M., Lin, M-F.G. and Bonk, C.J. (2007) 'OOPS, turning MIT opencourseware into Chinese: an analysis of a community of practice of global translators', International Review of Research in Open and Distance Learning, Vol. 8, pp.1-21.

Leimeister, J.M., Ebner, W. and Krcmar, H. (2005) 'Design, implementation, and evaluation of trust-supporting components in virtual communities for patients', J. Manage. Inf. Syst., Vol. 21, pp.101-131.

Leimeister, J.M., Sidiras, P. and Krcmar, H. (2004) 'Success factors of virtual communities from the perspective of members and operators: an empirical study', System Sciences, 2004. Proceedings of the 37th Annual Hawaii International Conference, 5-8 January 2004, 10pp. 
Lin, F-R., Lin, S-C. and Huang, T-P. (2008) 'Knowledge sharing and creation in a teachers' professional virtual community', Computers \& Education, Vol. 50, pp.742-756.

Lin, M-J.J., Hung, S-W. and Chen, C-J. (2009) 'Fostering the determinants of knowledge sharing in professional virtual communities', Computers in Human Behavior, Vol. 25, pp.929-939.

Liu, C-J. and Yang, S.C. (2012) 'Applying the practical inquiry model to investigate the quality of students' online discourse in an information ethics course based on Bloom's teaching goal and Bird's 3C model', Computers \& Education.

Ma, W.W.K. and Yuen, A.H.K. (2010) 'Understanding online knowledge sharing: an interpersonal relationship perspective', Computers \& Education, Vol. 56, pp.210-219.

Matzat, U. (2010) 'Reducing problems of sociability in online communities: integrating online communication with offline interaction', American Behavioral Scientist, Vol. 53, pp.1170-1193.

Mei-Hui, L. (2011) 'Discussing teaching videocases online: perspectives of preservice and inservice EFL teachers in Taiwan', Computers \& Education.

Napoli, L. (1998) 'The latest internet buzzword: community', New York Times.

Overbaugh, R.C. and Nickel, C.E. (2011) 'A comparison of student satisfaction and value of academic community between blended and online sections of a university-level educational foundations course', The Internet and Higher Education, Vol. 14, pp.164-174.

Parr, J. and Ward, L. (2006) 'Building on foundations: creating an online community', Journal of Technology and Teacher Education, Vol. 14, pp.775-793.

Peacock, S. and Hooper, J. (2007) 'E-learning in physiotherapy education', Physiotherapy, Vol. 93, pp.218-228.

Preece, J. (2001) 'Sociability and usability in online communities: determining and measuring success', Behaviour \& Information Technology, Vol. 20, pp.347-356.

Ritter, C., Polnick, B., Fink Ii, R. and Oescher, J. (2010) 'Classroom learning communities in educational leadership: a comparison study of three delivery options', The Internet and Higher Education, Vol. 13, pp.96-100.

Riverin, S. and Stacey, E. (2008) 'Sustaining an online community of practice: a case study', Journal of Distance Education, Vol. 22, pp.43-58.

Ross, D.A.R. (2007) 'Backstage with the knowledge boys and girls: Goffman and distributed agency in an organic online community', Organization Studies (01708406), Vol. 28, pp.307-325.

Rovai, A.P. (2003) 'The relationships of communicator style, personality-based learning style, and classroom community among online graduate students', The Internet and Higher Education, Vol. 6, pp.347-363.

Rovai, A.P. and Wighting, M.J. (2005) 'Feelings of alienation and community among higher education students in a virtual classroom', The Internet and Higher Education, Vol. 8, pp. 97-110.

Samarawickrema, G., Benson, R. and Brack, C. (2010) 'Different spaces: staff development for Web 2.0', Australasian Journal of Educational Technology, Vol. 26, pp.44-49.

Schellens, T. and Valcke, M. (2006) 'Fostering knowledge construction in university students through asynchronous discussion groups', Computers \& Education, Vol. 46, pp.349-370.

Shea, P. and Bidjerano, T. (2012) 'Learning presence as a moderator of cognitive presence in the community of inquiry model', Computers \& Education.

Shea, P., Hayes, S., Vickers, J., Gozza-Cohen, M., Uzuner, S., Mehta, R., Valchova, A. and Rangan, P. (2010) 'A re-examination of the community of inquiry framework: social network and content analysis', The Internet and Higher Education, Vol. 13, pp.10-21.

Sing, C.C. and Khine, M.S. (2006) 'An analysis of interaction and participation patterns in online community’, Educational Technology \& Society, Vol. 9, pp.250-261. 
Smith, G.G., Sorensen, C., Gump, A., Heindel, A.J., Caris, M. and Martinez, C.D. (2011) 'Overcoming student resistance to group work: online versus face-to-face', The Internet and Higher Education, Vol. 14, pp.121-128.

So, H-J. and Brush, T.A. (2008) 'Student perceptions of collaborative learning, social presence and satisfaction in a blended learning environment: relationships and critical factors', Computers \& Education, Vol. 51, pp.318-336.

Teng, D.C-E., Chen, N-S., Kinshuk and Leo, T. (2012) 'Exploring students' learning experience in an international online research seminar in the synchronous cyber classroom', Computers \& Education, Vol. 58, pp.918-930.

Thurmond, V. and Wambach, K. (2004) 'Understanding interactions in distance education: a review of the literature', International Journal of Instructional Technology and Distance Learning.

Tsai, C-W. (2010) 'Do students need teacher's initiation in online collaborative learning?', Computers \& Education, Vol. 54, pp.1137-1144.

Vavasseur, C.B. and Macgregor, S.K. (2008) 'Extending content-focused professional development through online communities of practice', Journal of Research on Technology in Education, Vol. 40, pp.517-536.

Vygotsky, L. (1988) 'The genesis of higher mental functions', Cognitive development to adolescence: a reader, pp. 61-79.

Wachter, R.M., Gupta, J.N.D. and Quaddus, M.A. (2000) 'IT takes a village: virtual communities in support of education', International Journal of Information Management, Vol. 20, pp.473-489.

Webster, J. and Watson, R. (2002) 'Analyzing the past to prepare for the future: writing a literature review’, MIS Quarterly, Vol. 26.

Wenger, E. (1998) 'Communities of practice: learning as a social system', Systems Thinker, Vol. 9, pp. $1-5$.

Wu, D. and Hiltz, S.R. (2004) 'Predicting learning from asynchronous online discussions', Journal of Asynchronous Learning Networks, Vol. 8.

Yang, Y-F., Yeh, H-C. and Wong, W-K. (2010) 'The influence of social interaction on meaning construction in a virtual community', British Journal of Educational Technology, Vol. 41, pp.287-306.

Yu, T-K., Lu, L-C. and Liu, T-F. (2010) 'Exploring factors that influence knowledge sharing behavior via weblogs', Computers in Human Behavior, Vol. 26, pp.32-41.

Zydney, J.M., Denoyelles, A. and Kyeong-Ju Seo, K. (2012) 'Creating a community of inquiry in online environments: an exploratory study on the effect of a protocol on interactions within asynchronous discussions', Computers \& Education, Vol. 58, pp.77-87. 